\title{
CONE BEAM COMPUTED TOMOGRAPHY ASSESSMENT OF THE RELATION BETWEEN SEX AND MORPHOLOGY OF MAXILLA IN PATIENTS WITH IMPACTED MAXILLARY CANINE
}

\author{
Waleed El Sayed Refaat* and Gihan Gamal El-Desouky**
}

\begin{abstract}
Maxillary canine impaction is a relatively common clinical problem and radiographic examination plays a crucial role in diagnosis and treatment planning.

Objective: To study the relation between sex and morphology of maxilla in patients with maxillary canine impaction using cone beam computed tomography (CBCT).

Material and methods: The study sample consisted of the CBCT records of 90 subjects obtained before any surgical or orthodontic intervention. The records were divided into 2 main groups, Group I: the male group, consisted of 44 subjects divided into three subgroups, I a: the normally erupting maxillary canine subgroup (control group), I b: the buccal impaction canine subgroup and I c: the palatal impaction canine subgroup. Similarly, Group II: the female group, consisted of 46 subjects also divided into three similar subgroups. From the CBCT images, the following measurements and ratios were obtained to assess the maxillary morphology: inter-molar width, arch length, palatal vault depth, maxillary transverse skeletal width and nasal cavity width, in addition to the ratio of arch length to inter-molar width and the ratio of palatal vault depth to inter-molar width.
\end{abstract}

Results: Upon comparing parameters between groups I and II: for both males and females in the normal erupting canine and the palatally impacted canine subgroups the only statistically significant difference was found in the inter-molar width and the arch length, while in the buccally impacted canine subgroups the palatal vault depth, the maxillary skeletal width and nasal cavity width showed statistically significant differences between the male and female groups. The ratio of arch length to inter-molar width showed no statistically significant difference between males and females in all sub-groups while the ratio of palatal vault depth to inter-molar width showed differences between males and females only in the buccal impaction subgroups.

Conclusion: The male subjects of the palatally impacted canine have a wider and longer dental arch than the female subjects of the same subgroup while the male subjects of the buccally impacted canine subgroup have a deeper palatal vault, wider skeletal arch and nasal cavity width than the female subjects of the same subgroup. However, there was no difference between both sexes regarding the shape of the maxillary arch in all subgroups. .

KEY WORDS: Impacted maxillary canines; CBCT; Maxillary arch width; Nasal cavity width

* Assistant Professor of Orthodontics., Faculty of Dentistry, Suez Canal University, Egypt.

** Assistant Professor of Oral Radiology, Faculty of Dentistry, Suez Canal University, Egypt. 


\section{INTRODUCTION}

Orthodontics is considered to be a complex problem-solving domain. The complexity of ectopic/impacted canines is further compounded by the scarcity of properly controlled clinical research. The permanent canine is considered one of the most important teeth in the dental arch, both aesthetically and functionally. It determines the shape of the dental arch, defines the contour of the mouth, maintains the harmony and symmetry of the occlusal relationship, and supports lateral movements and masticatory load. As a result of their high functional and esthetic value, mal-positioning and non-eruption of the canines represent significant sequelae of their ectopic eruption and impaction. ${ }^{1}$

The diagnosis and treatment of this problem requires much attention from the orthodontist for early diagnosis and management. It is prudent to distinguish between labially unerupted canines and palatally impacted canines. The palatal impaction is usually detected after the age of thirteen; surgical treatment is required, because palatally impacted canines very rarely erupt spontaneously. ${ }^{2}$ The prevalence of permanent maxillary canine impaction is approximately $1-3 \%$ of the population. ${ }^{1}$ Of all permanent maxillary canine impactions, palatal impactions occur two to three times more often than do buccal impactions. ${ }^{3}$ The palatally impacted canine (PDC) is more prevalent in females than in males, and unilateral impactions are more common than bilateral impactions. ${ }^{4}$

The impaction of the maxillary canine is a multifactorial problem. Several studies attempted to study the relationship between maxillary impacted canine position and maxillary morphology, their results often were contradictory. McConnell et al, ${ }^{5}$ measured inter-molar and intercanine widths in impacted maxillary canines patients using diagnostic casts in comparison with the controls and concluded that patients with impacted maxillary canines have transverse deficiencies in the anterior portion of the arch which was considered as a local cause for canine displacement. Schindel and Duffy ${ }^{6}$ also stated that maxillary transverse discrepancies increase the possibility of canine impaction. However, Al-Nimri and Gharaibeh ${ }^{7}$ reported that subjects with palatally impacted canines have greater maxillary transverse arch dimensions.

In 2012, Yoojun Kim et al ${ }^{8}$ carried out a study aiming to find whether there is a relationship between the position; buccally or palatally ; of impacted maxillary canines and the morphology of the maxilla. They concluded that the shape of the maxillary arch was narrower and longer in the palatally impacted canine group as compared with the buccally impacted canine group, while the palatally impacted canine group had a deeper palatal vault than did the buccally impacted canine group. However, they did not classify their study sample into males and females. In general, various sexrelated differences in size and shape of the dental arches have been reported. ${ }^{9}$

Nonetheless, it is still difficult to explain impaction of maxillary canines and whether or not a relationship exists between sex and maxillary morphology due to the scarcity of literature available in that specific topic. Therefore, the present work was carried out in an attempt to correlate sex with morphology of the maxilla in maxillary canine impaction patients.

\section{MATERIALS AND METHODS}

The study sample consisted of the CBCT records of 90 male and female subjects, ranging in age from 13 to 17 years. CBCT images were obtained from a private radiology center. Personal data concerning the patients other than age, sex and health condition were hidden out of respect of doctor-patient confidentiality. The protocol used in the present study was in accordance with the ethical and scientific guidelines of the Faculty of Dentistry, Suez Canal University.

Radiographs of the subjects included in the present study had to reveal the presence of the following inclusion criteria: - (1) Permanent maxillary canines (whether erupted, un-erupted with one year difference after all permanent teeth 
had erupted or impacted without obstruction as odontome) (2) The impacted maxillary canines were either unilateral or bilateral. (3) In case of unilateral impacted canines, eruption difference of more than 1 year compared with the canine on the opposite side. (4) Absence of skeletal congenital defects. (5) Pre-treatment images obtained before any orthodontic or surgical intervention.

All CBCT images were acquired using Planmeca ProMax ${ }^{\circledR}$ 3D Mid (Helsinki, Finland) using amorphous silicon flat panel sensor with cesium iodide scintillator, $0.2 \mathrm{~mm}$ focal spot size and 15 bit grey scale resolution. The operating parameters used for all scans of the study were $90 \mathrm{Kvp}, 12$ mAs, voxel size $0.2 \mathrm{~m}$, scanning time 12 seconds and $10 \times 12 \mathrm{~cm}$ FOV.

After acquisition, images were exported in DICOM files (Digital Imaging and Communications in Medicine) for image analysis using Planmeca Romexis ${ }^{\circledR}$ 3D_Mid Viewer version 3.8.1R. CBCT data was displayed on the software screen as axial, sagittal, coronal and 3D volume rendering images. The bucco-palatal position of the impacted canine was determined from the CBCT image with the lateral incisor root as the reference. ${ }^{8}$

For image analysis and distances calculation, orientation of the reference planes was performed as follows:

- The axial plane was aligned at the level of the maxillary occlusal plane, parallel to the marginal ridges and cusp tips of the premolars.

- The sagittal plane was oriented to the skeletal midsagittal plane.

- The coronal plane was oriented perpendicular to the axial and sagittal planes at the level of the premolars.

Subject grouping: The subjects were divided into 2 main groups, group I and group II.

Group I : The male group, consisted of 44 subjects divided into 3 subgroups, I a : the normally erupting maxillary canine group (control group) and included 17 subjects, I $\mathrm{b}$ : the buccal impaction canine group which included 13 subjects and I c : the palatal impaction canine group included 14 subjects.

Similarly, Group II : The female group, consisted of 46 subjects also divided into three subgroups, II a : the control group and included 13 subjects, II $\mathrm{b}$ : the buccal impaction canine group included 17 subjects and the palatal impaction canine group II c: included 16 subjects.

From all CBCT records, the following measurements were obtained:

1. The ratio of arch length to inter-molar width from the axial cut of CBCT records was the value used to compare the maxillary arch shapes between the 3 subgroups in the male and female groups. This ratio was computed by (arch length/ inter-molar width x 100). ${ }^{8}$ (Fig. 1.a)

2. The ratio of palatal vault depth to inter-molar width was used to compare the shape of the palate in the male and female groups. This ratio was computed by (palatal vault depth/intermolar width $\mathrm{x} \mathrm{100)}{ }^{8}$ from the CBCT coronal cut. (Fig 1.b)

3. Maxillary transverse skeletal width, (the horizontal distance from the jugale right to jugale left (JR-JL)) was obtained from the 3D reconstructed CBCT image. ${ }^{10,11}$ (Fig 2.a)

4. The width of the nasal cavity was measured from the coronal section of CBCT records. ${ }^{8}$

(Fig 2.b)

\section{Statistical analysis:}

The data were collected, tabulated, and analyzed. Descriptive statistics was calculated using Descriptive Statistics of SPSS. ${ }^{12}$ One way analysis of variance was used to test the effect of group on different measurements. Duncan Post-Hoc Multiple Comparisons (Post-Hoc) at $\mathrm{p} \leq 0.05$ was used for means comparison. 


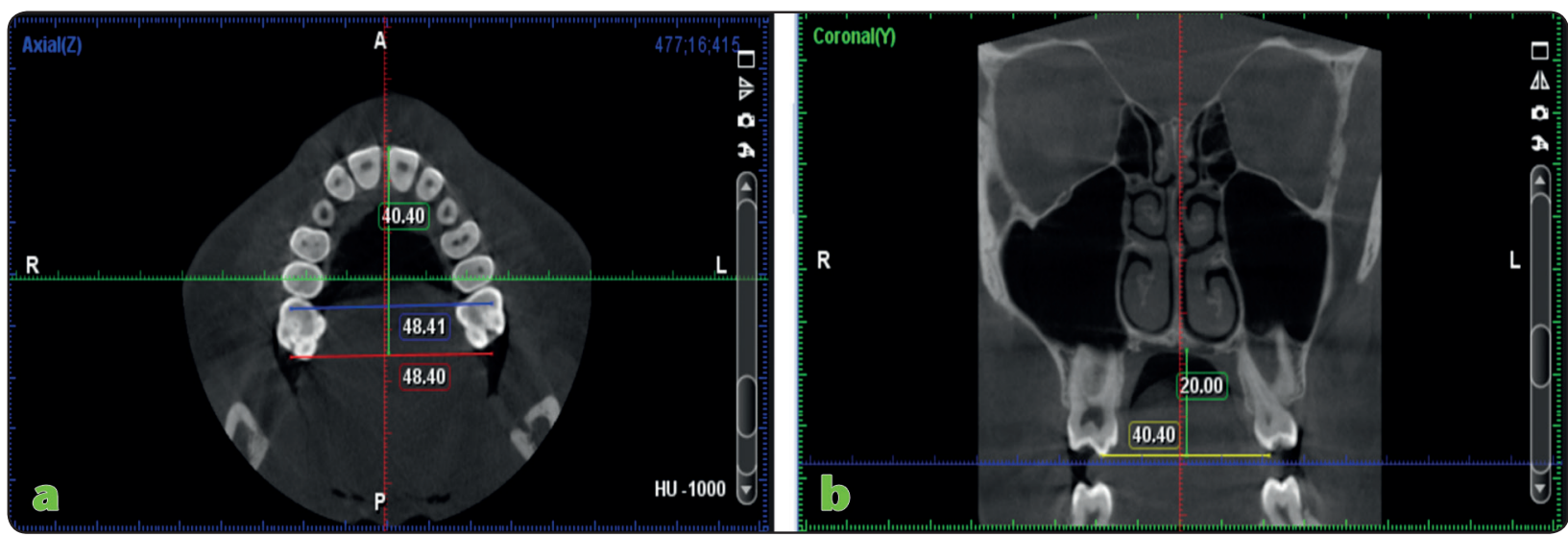

Fig. (1): a) Axial CBCT cut showing linear measurements of maxillary arch length (green line) and maxillary inter-molar width (blue line) . b) Coronal CBCT cut showing the measurements of palatal vault depth (green line) and line between mesiopalatal cusp tips of the right and left first molars (yellow line).

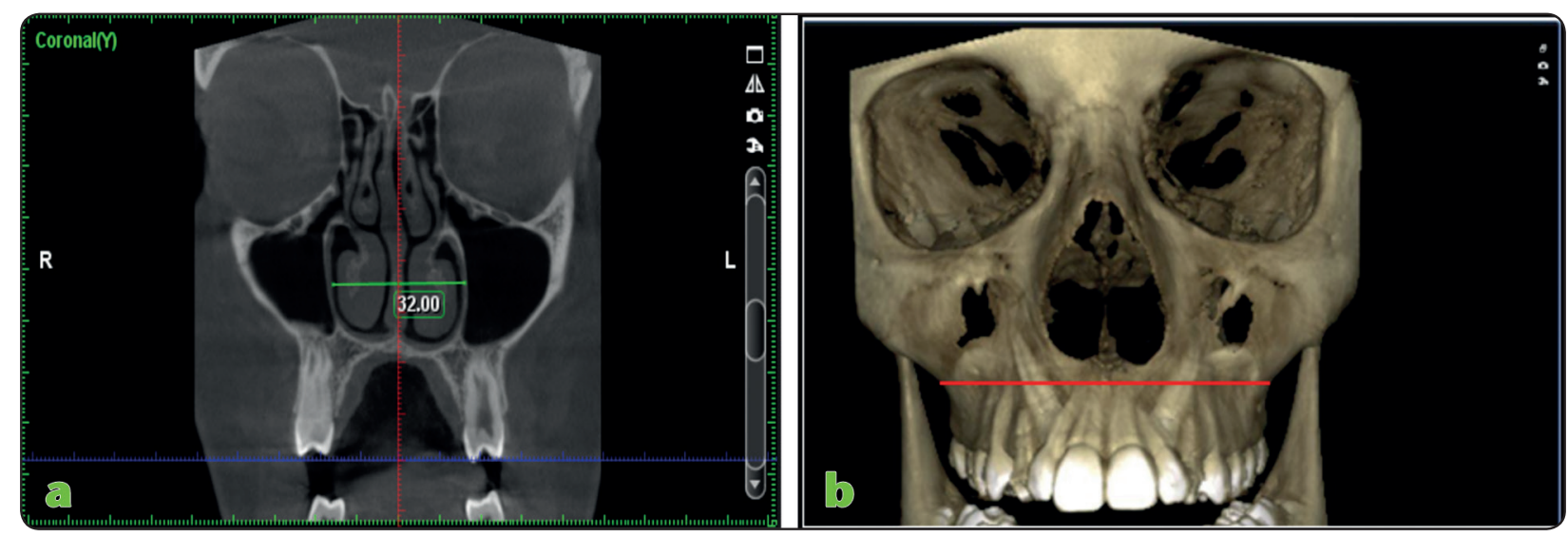

Fig. (2): a) 3D reconstructed CBCT image showing the measurement of maxillary transverse skeletal width (red line). b) Coronal CBCT cut showing the measurement of nasal cavity width (green line).

\section{RESULTS}

The average values and standard deviations for each parameter used for assessment of maxillary morphology in the different subgroups for male and female subjects are compared in tables (1 and 2).

Regarding the inter-molar width, for male group $\mathrm{I}$, in the buccal canine impaction subgroup I $\mathrm{b}$ there was statistically significant differences compared to other subgroups. On the other hand, the inter-molar width for female group II, showed no statistically significant differences among the 3 subgroups.

Regarding the arch length as an absolute distance for both male and female subjects, there was no statistically significant differences between the 3 subgroups.

However, the palatal vault as an absolute distance for both male and female subjects in the buccal canine impaction subgroups I $b$ and II $b$, showed statistically significant differences in relation to other subgroups, whereas the maxillary skeletal width showed no statistically significant differences in-between subgroups for male and female subjects.

On the other hand, nasal cavity width in the buccal canine impaction subgroups I b and II b showed statistically significant differences in relation to other subgroups. 
TABLE (1): Table showing the comparing measurements used for analysis of the maxillary morphology in the male and female groups

\begin{tabular}{|c|c|c|c|c|c|c|c|c|c|c|c|}
\hline \multirow{2}{*}{$\begin{array}{l}\text { Measurement } \\
(\mathrm{mm})\end{array}$} & \multicolumn{6}{|c|}{ Male (I) } & \multicolumn{5}{|c|}{ Female (II) } \\
\hline & Group & Mean & S.D. & Min. & Max. & dt & Mean & S.D. & Min. & Max. & $\mathrm{dt}$ \\
\hline \multirow{3}{*}{$\begin{array}{l}\text { Inter-molar } \\
\text { width }\end{array}$} & Normal & 52.059 & 3.418 & 45.000 & 56.000 & $\mathrm{a}$ & 48.000 & 3.136 & 44.000 & 53.000 & $\mathrm{a}$ \\
\hline & Buccal & 49.154 & 3.412 & 44.000 & 54.000 & $\mathrm{~b}$ & 48.059 & 2.926 & 45.000 & 54.000 & $\mathrm{a}$ \\
\hline & Palatal & 52.643 & 3.650 & 44.000 & 56.000 & $\mathrm{a}$ & 47.938 & 2.489 & 44.000 & 51.000 & $\mathrm{a}$ \\
\hline \multirow{3}{*}{ Arch length } & Normal & 38.882 & 2.369 & 33.000 & 43.000 & $\mathrm{a}$ & 36.231 & 2.279 & 32.000 & 40.000 & $\mathrm{a}$ \\
\hline & Buccal & 37.692 & 3.066 & 33.000 & 44.000 & $\mathrm{a}$ & 36.941 & 2.772 & 35.000 & 44.000 & $\mathrm{a}$ \\
\hline & Palatal & 38.714 & 2.614 & 32.000 & 42.000 & $\mathrm{a}$ & 36.188 & 2.167 & 31.000 & 39.000 & $\mathrm{a}$ \\
\hline \multirow{3}{*}{$\begin{array}{l}\text { Palatal vault } \\
\text { Depth }\end{array}$} & Normal & 20.941 & 3.400 & 15.000 & 26.000 & $\mathrm{a}$ & 20.923 & 2.178 & 17.000 & 25.000 & $\mathrm{a}$ \\
\hline & Buccal & 19.308 & 1.797 & 16.000 & 22.000 & $\mathrm{~b}$ & 17.000 & 2.550 & 14.000 & 22.000 & $\mathrm{~b}$ \\
\hline & Palatal & 20.429 & 3.413 & 16.000 & 25.000 & $\mathrm{a}$ & 20.688 & 2.152 & 17.000 & 25.000 & $\mathrm{a}$ \\
\hline \multirow{3}{*}{$\begin{array}{l}\text { Maxillary } \\
\text { Width }\end{array}$} & Normal & 61.412 & 5.680 & 48.000 & 72.000 & $\mathrm{a}$ & 57.769 & 6.030 & 48.000 & 65.000 & $\mathrm{a}$ \\
\hline & Buccal & 60.462 & 3.382 & 57.000 & 65.000 & $\mathrm{a}$ & 57.765 & 3.270 & 54.000 & 65.000 & $\mathrm{a}$ \\
\hline & Palatal & 62.071 & 5.636 & 48.000 & 71.000 & $\mathrm{a}$ & 58.000 & 5.865 & 48.000 & 66.000 & $\mathrm{a}$ \\
\hline \multirow{3}{*}{ Nasal width } & Normal & 32.353 & 1.902 & 28.000 & 36.000 & $\mathrm{a}$ & 31.769 & 2.619 & 27.000 & 36.000 & $\mathrm{a}$ \\
\hline & Buccal & 29.538 & 3.205 & 25.000 & 36.000 & $\mathrm{~b}$ & 26.706 & 2.201 & 24.000 & 31.000 & $\mathrm{~b}$ \\
\hline & Palatal & 32.500 & 2.245 & 27.000 & 36.000 & $\mathrm{a}$ & 31.625 & 2.277 & 27.000 & 35.000 & $\mathrm{a}$ \\
\hline
\end{tabular}

S.D. = Standard deviation .

Min. = Minimum value .

Max. = Maximum value

$d t \quad=$ Duncan's Multiple Range Test for the effect of group.

Means with the same letter within each measurement are not significantly different at $p=0.05$.

TABLE (2): Table showing the comparing ratios used for analysis of the maxillary morphology in the male and female groups

\begin{tabular}{|c|c|c|c|c|c|c|c|c|c|c|c|}
\hline \multirow{2}{*}{ Measurement } & \multicolumn{6}{|c|}{ Male (I) } & \multicolumn{5}{|c|}{ Female (II) } \\
\hline & Group & Mean & S.D. & Min. & Max. & dt & Mean & S.D. & Min. & Max. & $\mathrm{dt}$ \\
\hline \multirow{3}{*}{$\begin{array}{l}\text { Arch length/ } \\
\text { inter-molar width }\end{array}$} & Normal & 74.958 & 5.080 & 68.140 & 85.930 & $\mathrm{a}$ & 75.755 & 5.449 & 68.370 & 88.030 & $\mathrm{a}$ \\
\hline & Buccal & 77.265 & 6.303 & 67.090 & 86.970 & $\mathrm{a}$ & 77.474 & 7.740 & 66.770 & 95.330 & $\mathrm{a}$ \\
\hline & Palatal & 74.216 & 5.142 & 66.490 & 87.840 & $\mathrm{a}$ & 75.431 & 5.441 & 67.410 & 88.030 & $\mathrm{a}$ \\
\hline \multirow{3}{*}{$\begin{array}{c}\text { Palatal vault } \\
\text { depth/inter-molar }\end{array}$} & Normal & 40.568 & 7.563 & 27.210 & 53.970 & $\mathrm{a}$ & 43.873 & 6.326 & 33.720 & 52.620 & $\mathrm{a}$ \\
\hline & Buccal & 39.527 & 4.772 & 33.040 & 48.810 & $\mathrm{a}$ & 35.452 & 5.624 & 30.730 & 47.880 & $\mathrm{~b}$ \\
\hline & Palatal & 39.206 & 7.841 & 28.350 & 52.000 & $\mathrm{a}$ & 43.175 & 5.799 & 33.720 & 51.830 & $\mathrm{a}$ \\
\hline
\end{tabular}

S.D. = Standard deviation .

Min. = Minimum value .

Max. = Maximum value .

$d t=$ Duncan's Multiple Range Test for the effect of group .

Means with the same letter within each measurement are not significantly different at $p=0.05$. 
Upon comparing the arch length as a relative ratio, (the arch length /inter-molar width x100) no statistically significant difference was found among all subgroups in both male and female groups, while, the palatal vault as a relative ratio (the palatal vault depth/inter-molar width x100) showed statistically significant differences in the buccal impaction subgroup II b only in relation to other female subgroups.

Comparison between male and female groups I and II regarding the measurements and ratios used for analysis of maxillary morphology in all subgroups is presented in tables (3 and 4).

In the normal erupting canine and the palatally impacted canine subgroups, the inter-molar width and the arch length as an absolute distance showed statistically significant differences between males and females, while the palatal vault depth, the maxillary skeletal width and nasal cavity width showed no statistically significant differences between groups I and II.
In contrast, regarding the buccally impacted canine subgroups, the inter-molar width and the arch length as an absolute distance showed no statistically significant differences between the male and female subjects. However, statistically significant differences were found upon comparison of the palatal vault depth, the maxillary skeletal width and nasal cavity width between groups I and II.

No statistically significant differences were found in the comparison of the arch length as a relative ratio (the arch length /inter-molar width x100) among all subgroups, indicating no differences in the shapes of maxillary arches between the male and female subjects in the normally erupting canine subgroups, the buccally impacted canine subgroups and the palatally impacted canine subgroups.

On the other hand, upon comparing the palatal vault as a relative ratio (the palatal vault depth/ inter-molar width $\mathrm{x} 100$ ) between the males and females among all subgroups, the only statistically significant differences was found in the buccally impacted canine subgroups.

TABLE (3) Table showing the comparison between males and females regarding different measurements used for analysis of the maxillary morphology in all subgroups.

\begin{tabular}{|c|c|c|c|c|c|c|c|c|c|c|c|c|c|c|c|}
\hline \multirow{4}{*}{$\begin{array}{c}\text { Variables } \\
\text { Measurement }\end{array}$} & \multicolumn{5}{|c|}{ Normal group } & \multicolumn{5}{|c|}{ Buccal group } & \multicolumn{5}{|c|}{ Palatal group } \\
\hline & \multicolumn{5}{|c|}{ Sex } & \multicolumn{5}{|c|}{ Sex } & \multicolumn{5}{|c|}{ Sex } \\
\hline & \multicolumn{2}{|c|}{ Male (I) } & \multicolumn{2}{|c|}{ Female (II) } & \multirow{2}{*}{$\begin{array}{c}\mathrm{P}- \\
\text { value }\end{array}$} & \multicolumn{2}{|c|}{ Male (I) } & \multicolumn{2}{|c|}{ Female (II) } & \multirow{2}{*}{$\begin{array}{c}\mathrm{P}- \\
\text { value }\end{array}$} & \multicolumn{2}{|c|}{ Male (I) } & \multicolumn{2}{|c|}{ Female (II) } & \multirow{2}{*}{$\begin{array}{c}\mathrm{P}- \\
\text { value }\end{array}$} \\
\hline & Mean & S.D. & Mean & S.D. & & Mean & S.D. & Mean & S.D. & & Mean & S.D. & Mean & S.D. & \\
\hline $\begin{array}{l}\text { Inter-molar } \\
\text { width }\end{array}$ & 52.06 & 3.418 & 48.00 & 3.136 & $\begin{array}{c}0.002 \\
* *\end{array}$ & 49.15 & 3.412 & 48.06 & 2.926 & $\begin{array}{c}0.352 \\
\text { NS }\end{array}$ & 52.64 & 3.650 & 47.94 & 2.489 & $\begin{array}{r}0.001 \\
* * *\end{array}$ \\
\hline Arch length & 38.88 & 2.369 & 36.23 & 2.279 & $\begin{array}{c}0.005 \\
* *\end{array}$ & 37.69 & 3.066 & 36.94 & 2.772 & $\begin{array}{c}0.488 \\
\text { NS }\end{array}$ & 38.71 & 2.614 & 36.19 & 2.167 & $\begin{array}{c}0.007 \\
* *\end{array}$ \\
\hline $\begin{array}{c}\text { Palatal vault } \\
\text { depth }\end{array}$ & 20.94 & 3.400 & 20.92 & 2.178 & $\begin{array}{c}0.987 \\
\mathrm{NS}\end{array}$ & 19.31 & 1.797 & 17.00 & 2.550 & $\begin{array}{c}0.010 \\
* * \\
\end{array}$ & 20.43 & 3.413 & 20.69 & 2.152 & $\begin{array}{c}0.803 \\
\text { NS } \\
\end{array}$ \\
\hline $\begin{array}{l}\text { Maxillary } \\
\text { width }\end{array}$ & 61.41 & 5.680 & 57.77 & 6.030 & $\begin{array}{c}0.101 \\
\mathrm{NS}\end{array}$ & 60.46 & 3.382 & 57.76 & 3.270 & $\begin{array}{c}0.036 \\
*\end{array}$ & 62.07 & 5.636 & 58.00 & 5.865 & $\begin{array}{c}0.064 \\
\text { NS }\end{array}$ \\
\hline Nasal width & 32.35 & 1.902 & 31.77 & 2.619 & $\begin{array}{c}0.485 \\
\mathrm{NS}\end{array}$ & 29.54 & 3.205 & 26.71 & 2.201 & $\begin{array}{c}0.008 \\
* *\end{array}$ & 32.50 & 2.245 & 31.63 & 2.277 & $\begin{array}{c}0.300 \\
\text { NS }\end{array}$ \\
\hline
\end{tabular}

S.D. = Standard deviation .

NS = Insignificant $(p>0.05)$.
$P=$ Probability level for the effect of sex (Student t test).

$$
* *=\text { Significant at } p \leq 0.01
$$


TABLE (4): Table showing the comparison between males and females regarding ratios used for analysis of the maxillary morphology in the different subgroups.

\begin{tabular}{|c|c|c|c|c|c|c|c|c|c|c|c|c|c|c|c|}
\hline \multirow{2}{*}{ Variables } & \multicolumn{4}{|c|}{ Normal group } & & \multicolumn{4}{|c|}{ Buccal group } & & \multicolumn{4}{|c|}{ Palatal group } & \\
\hline & \multicolumn{4}{|c|}{ Sex } & & \multicolumn{4}{|c|}{ Sex } & & \multicolumn{4}{|c|}{ Sex } & \\
\hline \multirow{2}{*}{ Ratio } & \multicolumn{2}{|c|}{ Male (I) } & \multicolumn{2}{|c|}{ Female (II) } & \multirow{2}{*}{$\begin{array}{c}\mathrm{P}- \\
\text { value }\end{array}$} & \multicolumn{2}{|c|}{ Male (I) } & \multicolumn{2}{|c|}{ Female (II) } & \multirow{2}{*}{$\begin{array}{c}\mathrm{P}- \\
\text { value }\end{array}$} & \multicolumn{2}{|c|}{ Male (I) } & \multicolumn{2}{|c|}{ Female (II) } & \multirow{2}{*}{$\begin{array}{c}\mathrm{P}- \\
\text { value }\end{array}$} \\
\hline & Mean & S.D. & Mean & S.D. & & Mean & S.D. & Mean & S.D. & & Mean & S.D. & Mean & S.D. & \\
\hline $\begin{array}{l}\text { Arch length/ } \\
\text { Inter-molar } \\
\text { width }\end{array}$ & 74.96 & 5.080 & 75.75 & 5.449 & $\begin{array}{c}0.683 \\
\text { NS }\end{array}$ & 77.27 & 6.303 & 77.47 & 7.740 & $\begin{array}{c}0.938 \\
\mathrm{NS}\end{array}$ & 74.22 & 5.142 & 75.43 & 5.441 & $\begin{array}{c}0.536 \\
\mathrm{NS}\end{array}$ \\
\hline $\begin{array}{l}\text { Palatal vault } \\
\text { depth/ } \\
\text { Inter-molar } \\
\text { width }\end{array}$ & 40.57 & 7.563 & 43.87 & 6.326 & $\begin{array}{c}0.214 \\
\mathrm{NS}\end{array}$ & 39.53 & 4.772 & 35.45 & 5.624 & $\begin{array}{c}0.045 \\
*\end{array}$ & 39.21 & 7.841 & 43.18 & 5.799 & $\begin{array}{c}0.123 \\
\mathrm{NS}\end{array}$ \\
\hline
\end{tabular}

S.D. = Standard deviation

$P=$ Probability level for the effect of sex (Student t test).

$N S=$ Insignificant $(p>0.05)$.

$* *=$ Significant at $p \leq 0.01$.

\section{DISCUSSION}

Although many studies have been conducted to examine the relationship between maxillary impacted canines and discrepancies in the maxillary morphology, the results of these studies were often inconclusive and contradictory. ${ }^{5,6}$ In addition, most of these studies used measurements derived from stone casts for comparisons. Up to our knowledge, no previous studies assessed the maxillary morphology differences in impacted maxillary canines between males and females using cone beam computed tomography (CBCT).

Early diagnosis of the impacted maxillary canine is necessary to ensure better treatment results, ${ }^{13}$ therefore, subjects included in the present study were chosen to range from 13 to 17 in age. In addition, the CBCT examination was undertaken before any surgical or orthodontic intervention to prevent the potential effect of treatment on the shape of the maxillary arch and the obtained measurements. ${ }^{8}$

Recently, orthodontists have been utilizing cone beam computed tomography (CBCT) to diagnose impacted teeth since it overcomes the superimpositions inherent in two dimensional imaging and provides a number of advantages over conventional CT; rapid scanning time, image accuracy, user friendly soft-ware, lower irradiation dose and lower cost. ${ }^{14}$

The present study used several parameters for assessing the maxillary morphology in different impacted canine positions in comparison to the controls. These parameters were further used for comparison between the main male and female groups under investigation.

For male subjects, the inter-molar width of the buccally impacted canine subgroup was significantly less than either both the palatally impacted canine and the control subgroups. These results were in agreement with Al-Nimri and Gharaibeh ${ }^{7}$ and Larsen $\mathrm{HJ}$ et al ${ }^{15}$ but contrary to another study conducted by Yoojun Kim et al, ${ }^{8}$ who found that the palatally impacted canine showed significantly lower inter-molar width when compared to the buccally impacted canines. However, their results were directly measured from the diagnostic models not from radiographs, in addition, they did not divide their subjects into males and females. 
On the other hand, the inter-molar width in the female group showed a non-statistically significant difference between the 3 subgroups, which was in agreement with Fattahi et al ${ }^{16}$ and Yan et al ${ }^{11}$ who concluded that the inter-molar width was similar in both impaction groups (buccal impaction and palatal impaction) and the control group.

Results of the present study showed a nonstatistically significant difference among all subgroups for both male and female subjects, regarding the arch length and the maxillary transverse skeletal width. These results were in agreement with Yoojun Kim et al ${ }^{8}$, Jacoby ${ }^{17}$, Stellzig et al ${ }^{18}$ and Anic-Milosevic. ${ }^{19}$ However, Fattahi et al ${ }^{16}$ revealed contrary results to our study; they observed that arch length was greater in the buccal impaction group compared with the control group. This difference may be due to that they measured the arch length from the study cast while in the present study, measurements were obtained from CBCT images. Regarding maxillary skeletal width, our results showed no differences between the three subgroups in both male and female subjects, which was in agreement with Saiar et al ${ }^{10}$, Yan et al ${ }^{11}$ and Hong et al ${ }^{20}$. Therefore, it could be concluded that the maxillary transverse width was not an etiologic factor contributing to the position of impacted maxillary canine, in addition, the presence of impacted canine has no effect on maxillary width.

For both male and female subjects in the present study, palatal vault depth as an absolute distance and nasal cavity width were found to be significantly smaller in the buccally impacted canine subgroup in comparison to the other two subgroups. This finding suggested that, the width of the nasal cavity might have an effect on the position of the maxillary canine tooth germ. The present result was agreement with Saiar et al ${ }^{10}$, who reported that there was no statistically significant difference in the width of the nasal cavity measured on posteroanterior cephalograms.
Yoojun Kim et al ${ }^{8}$ were in agreement with our results regarding the palatal vault depth, but they disagreed with our finding regarding the nasal cavity width and reported that no statistically significant difference existed in the nasal cavity width. However, in their study, measurements were obtained from computed tomography images not CBCT images.

On the other hand, according to Fattahi et al ${ }^{16}$, the palatal vault depth was similar in subjects with an impacted canine whether buccal or palatal and in matched controls, which was in disagreement to our results. This difference could be explained by that in their study, palatal depth was measured on the scaled vertical axis of a Korkhaus three-dimensional divider using the study cast.

Regarding the shape of the maxillary arch and the shape of the palatal vault, in the present study, the relative ratio of arch length/inter-molar width and the ratio of palatal vault depth to inter-molar width were used to compare the morphology of the maxilla and the shape of the palate respectively because the relative ratio seems to be more suitable in comparing morphological patterns and shapes than the absolute distance ${ }^{8}$.

Results of our study showed a non-statistically significant difference in the shape of maxillary arch between the 3 subgroups for both male and female subjects, indicating that the dental maxillary arch did not differ whether the canine was normally erupted or impacted. These results disagreed with Yoojun Kim et al ${ }^{8}$ who reported that the shape of the maxillary arch was wider and shorter in the buccally impacted canine group compared with the palatally impacted canine group. Again, this difference in the results of the maxillary arch shape may be attributed to that their parameters were directly measured from the diagnostic model not from CBCT images.

For male subjects in our study, the value corresponding to the shape of the palatal vault showed non-statistically significant difference 
between the 3 subgroups. This finding was in agreement with Fattahi et al. ${ }^{16}$ In contrast, for the female group, the value corresponding to the shape of the palatal vault showed a statistically significant difference between the 3 subgroups, indicating that the palatal vault of the buccally impacted canine subgroup was shallower compared with the palatally impacted canine and the control subgroups. This finding was in agreement with Yoojun Kim et al. ${ }^{8}$ From the previous results, it could be concluded that the palatal shape of female subjects is more related to the presence and position of impacted canines than the male subjects.

The parameters used to describe the maxillary morphology were again used to assess differences between both sexes in the different impacted canine positions and the controls.

The inter-molar width, in both the normal erupting canine and the palatally impacted canine subgroups, showed significantly greater values in the male groups denoting greater maxillary transverse dimension in comparison with the female group. This finding was in agreement with those of Laine and Hausen ${ }^{9}$ and Tsai and Tan, ${ }^{21}$ who found that the females had a statistically significantly narrower upper dental arch width than did males in normally erupting canine subgroup. On the other hand, no statistically significant differences was found between the male and female subjects in the buccally impacted canine subgroups.

Similarly, the male subjects had a greater arch length than the female subjects for both the normal erupting canine and the palatally impacted canine subgroups. The present finding was in agreement with Ahmad ${ }^{22}$ who reported insignificantly larger palatal length dimensions in males than females in normal erupting canine subjects but in disagreement with Tadinada et al ${ }^{23}$ who found that there was no statistically significant difference in arch length between the male and female subjects in the palatally impacted canine subgroups. In contrast, no statistically significant differences was found between the male and female subjects in the buccally impacted canine subgroups.

In the present study, there was a non-statistically significant differences regarding the palatal vault depth, maxillary transverse skeletal width and the nasal cavity width between the male and female subjects for both the normal erupting canine and the palatally impacted canine subgroups. This finding was in agreement with Tsai and Tan ${ }^{21}$ who found that there were no significant differences in palatal depth between males and females, but in disagreement with Laine and Hausen ${ }^{9}$ who described higher palates in males when compared to females in normal erupting canines. Also this finding was in agreement with Anic-Milosevic ${ }^{19}$ who found that there was no statistically significant difference in regards to palatal height for both genders in patients with palatally displaced maxillary canines concluding that the height of the palate may not have implications regarding the aetiology of palatally impacted canines. On the other hand, the male subjects had deeper palatal vault, greater maxillary skeletal transverse width and greater nasal cavity width than the female subjects in the buccally impacted canine subgroups.

Regarding the shape of the maxillary arch, the results showed a non-statistically significant difference between male and female subjects among the 3 subgroups. On the other hand, regarding the shape of the palatal vault for both the normal erupting canine and the palatally impacted canine subgroups, the males and females showed similar results, while in the buccally impacted canine subgroup, the male subjects had a deeper palatal vault than the female subjects.

The current investigation has revealed the presence of sexual dimorphism in the maxillary morphology of impacted canines. This important finding emphasizes the need to investigate male and female subjects separately and not as a combined group. When male and female groups are combined 
and studied as a whole, without subdividing them by gender, important features of the morphology are likely to be obscured. However, results of the current study suggests that morphology of the maxilla was more dependent on the position of the impacted canine rather than on the sex of the patient.

\section{CONCLUSION}

The present study compared features that described maxillary morphology between young male and female subjects in different impacted canine positions and controls. The following conclusions could be drawn:

-The male subjects had greater inter-molar width and arch length, similar palatal vault depth (as an absolute distance and as a relative ratio), maxillary transverse skeletal width, nasal cavity width and similar shape of the maxillary arch in comparison with the female subjects of both the control and the palatally impacted canine subgroups.

-The male subjects had greater palatal vault depth (as an absolute distance and as a relative ratio), maxillary transverse skeletal width and nasal cavity width, similar inter-molar width and similar arch length (as an absolute distance and as a relative ratio) in comparison with the female subjects of the buccally impacted canine subgroups.

\section{REFERENCES}

1. Becker A. The Orthodontic Treatment of Impacted Teeth. St Louis, Mo: Mosby-Year Book; 1998.

2. Dewel BF. The Upper Cuspid: Its Development and Impaction. The Angle Orthodontist 1949; 19(2): 79-79-90.

3. Bishara SE. Impacted maxillary canines: a review. Am J Orthod Dentofacial Orthop. 1992;101:159-171.

4. Peck S, Peck L, Kataja M. The palatally displaced canine as a dental anomaly of genetic origin. Angle Orthod. 1994;64:249-256.

5. McConnell TL, Hoffman DL, Forbes DP, Janzen EK, Weintraub NH. Maxillary canine impaction in patients with transverse maxillary deficiency. ASDC J Dent Child 1996; 63: 190-5
6. Schindel RH, Duffy SL. Maxillary transverse discrepancies and potentially impacted maxillary canines in mixeddentition patients. Angle Orthod 2007; 77:430-5.

7. Al-Nimri K, Gharaibeh T. Space conditions and dental and occlusal features in patients with palatally impacted maxillary canines: an aetiological study. European Journal of Orthodontics 2005; 27:461-5.

8. Yoojun Kim, Hong-Keun Hyun, and Ki-Taeg Jang. Interrelationship between the position of impacted maxillary canines and the morphology of the maxilla. Am J Orthod Dentofacial Orthop 2012; 141:556-62.

9. Tellervo Laine and Hannu Hausen.Alveolar arch dimensions, orthodontic treatment and absence of permenant teeth among Finnish students. An epidemiologic study. The Angle orthodontist. July, 1985; 55 (3): 225-233.

10. Saiar M, Rebellato J, Sheats RD. Palatal displacement of canines and maxillary skeletal width. Am J Orthod Dentofacial Orthop. 2006; 129:511-519.

11. Yan B, Sun Z, Fields H, Wang L, Luo L. Etiologic factors for buccal and palatal maxillary canine impaction: a perspective based on cone-beam computed tomography analyses. Am J Orthod Dentofacial Orthop. 2013; 143:527-534.

12. SPSS (2008): Statistical Package for the Social Sciences, Release 17.0.0, August 23, 2008.

13. Richardson G, Russell KA. A review of impacted permanent maxillary cuspids- diagnosis and prevention. J Can Dent Assoc 2000; 66(9): 497-501.

14. Botticelli S, Verna C, Paolo M. Cattaneo, Heidmann J and Melsen B. Two- versus three-dimensional imaging in subjects with unerupted maxillary canines. Eur J Orthod 2011; 33: 344-349.

15. Larsen HJ, Sørensen HB, Artmann L, Christensen IJ, Kjær I. Sagittal, vertical and transversal dimensions of the maxillary complex in patients with ectopic maxillary canines. Orthod Craniofac Res 2010;13:34-39.

16. Hamidreza Fattahi, Fatemeh Ghaeed and Abbas Alipour. Association between maxillary canine impaction and arch dimensions. Australian Orthodontic Journal 2012; 28:57-62.

17. Jacoby $\mathrm{H}$. The etiology of maxillary canine impactions. Am J Orthod Dentofacial Orthop. 1983;84:125-132. 
18. Stellzig A, Basdra EK, Komposch G. The etiology of canine tooth impaction--a space analysis. Fortschr Kieferorthop 1994; 55: 97-103.

19. Sandra Anic-Milosevic, Suzana Varga, Senka Mestrovic , Marina Lapter-Varga and Mladen Slaj. Dental and occlusal features in patients with palatally displaced maxillary canines. European Journal of Orthodontics 31 (2009) 367-373. doi:10.1093/ejo/cjp014

20. Wei-Hsin Hong, Rebecca Radfar, and Chun-Hsi Chung. Relationship between the maxillary transverse dimension and palatally displaced canines: A cone-beam computed tomographic study. Angle Orthod 2015; 85(3): 440-445.
21. Hung-Huey Tsai and Ching-Ting Tan. Morphology of the Palatal Vault of Primary Dentition in Transverse View. Angle Orthod 2004;74:774-779.

22. Zeina M Ahmad. Palatal Dimensions and Its correlation with the circumference of upper anterior teeth. Al-Rafidain Dent J. 2009; 9(2): 259- 267.

23. Aditya Tadinada, Mina Mahdian, Meenakshi Vishwanath, Veerasathpurush Allareddy, Madhur Upadhyay and Sumit Yadav . Evaluation of alveolar bone dimensions in unilateral palatally impacted canine: a cone beam computed tomographic analyses. European Journal of Orthodontics, 2015, Vol. 37, No. 6. 